\title{
PEMILIHAN BAHASA ETNIK BUGIS DALAM RANAH KELUARGA BERDASARKAN HUBUNGAN PERAN DAN KATEGORI PEKERJAAN DI KABUPATEN DONGGALA
}

\author{
ELECTION OF BUGIS ETNIC LANGUAGE IN THE FAMILY PLAN \\ BASED ON RELATIONSHIP RELATIONS AND JOB CATEGORIES \\ IN DONGGALA REGENCY
}

\author{
Tamrin \\ Balai Bahasa Provinsi Sulawesi Tengah \\ Jalan Untad I, Bumi Roviga, Tondo, Palu 94118 \\ Telepon (0451) 4705498; 421874, Ponsel: 085240066115 \\ Pos-el: thamrin21@ymail.com
}

\begin{abstract}
Abstrak
Pemilihan bahasa (language choice) merupakan fenomena yang lazim terjadi pada masyarakat multibahasa. Dengan mengangkat kasus pemilihan bahasa etnik Bugis dalam ranah keluarga berdasarkan hubungan peran dan kategori pekerjaan di Kabupaten Donggala, penelitian ini bertujuan untuk (1) mendeskripsikan pola pemilihan bahasa etnik Bugis dalam ranah keluarga berdasarkan kategori pekerjaan dan hubungan peran di Kabupaten Donggala, (2) mendeskripsikan pengaruh pekerjaan terhadap pemilihan bahasa etnik Bugis di Kabupaten Donggala dan (3) menganalisis faktor-faktor yang mendasari pemilihan bahasa etnik Bugis dalam ranah keluarga berdasarkan kategori pekerjaan dan hubungan peran di Kabupaten Donggala. Metode yang digunakan adalah pendekatan sosiolinguistik dengan teknik kuesioner, wawancara, pengamatan, dan perekaman, kemudian dianalisis berdasarkan presentase pola pemilihan bahasa etnik Bugis dalam ranah keluarga. Hasil analisis menunjukkan bahwa etnik Bugis di Kabupaten Donggala masih dominan memilih bahasa Bugis sebagai alat komunikasi dalam ranah keluarga berdasarkan hubungan peran dan kategori pekerjaan. Responden yang bekerja sebagai PNS/TNI/Polri serta pelajar yang memiliki presentase lebih rendah dalam pimilihan bahasa Bugisnya.
\end{abstract}

Kata kunci: pemilihan bahasa, ranah keluarga, kategori pekerjaan, bahasa Bugis, faktor sosial

\begin{abstract}
Language selection is a phenomenon that is common in multilingual societies. By taking the case of Bugis ethnic language selection in the family domain based on the relationship of roles and occupation categories in Donggala District, this study aims to (1) describe the pattern of Bugis ethnic language selection in the family sphere by occupation category and role relations in Donggala District, (2) to describe the influence of work on Bugis ethnic language election in Donggala District and (3) to analyze the factors underlying the selection of Bugis ethnic languages in the family sphere by occupation category and role relations in Donggala District. The method used is a sociolinguistic approach with questionnaires, interviews, observations, and recording techniques, then analyzed based on the percentage pattern of Bugis ethnic language selection in the family realm. The result of the analysis shows that Bugis
\end{abstract}


ethnic in Donggala Regency still dominantly choose Bugis language as communication tool in family domain based on the relation of role and occupation category. Respondents who work as civil servants / military / police and students who have a lower percentage in Bugisnya language electives.

Keywords: language selection, family domain, occupation category, Bugis

\section{Pandahuluan}

Pemilihan bahasa menurut Fasold (1984: 180), yaitu memilih "sebuah bahasa secara keseluruhan" (whole language) dalam suatu komunikasi. Seseorang yang menguasai dua bahasa atau lebih harus memilih bahasa mana yang akan ia gunakan. Misalnya, seseorang yang mengusai bahasa Bugis dan bahasa Indonesia, harus memilih salah satu di antara kedua bahasa itu ketika berbicara kepada orang lain dalam peristiwa komunikasi.

Dalam hal memilih bahasa terdapat tiga jenis pilihan, pertama dengan memilih satu variasi dari bahasa yang sama (intra-language-variation), apabila seorang penutur bahasa Bugis berbicara kepada kepala desa dengan menggunakan bahasa Bugis, maka ia telah melakukan pilihan bahasa yang pertama. Kedua, dengan alih kode (code-swicthing), artinya menggunakan satu bahasa pada satu keperluan dan menggunakan bahasa yang lain pada keperluan lain. Ketiga, dengan melakukan campur kode (codemixing), artinya menggunakan satu bahasa tertentu dengan dicampuri serpihan-serpihan dari bahasa lain.

Sejalan dengan hal tersebut ErvinTrip, (dalam Grosjean 1982: 136) berpendapat tentang faktor yang berpengaruh dalam pemilihan bahasa. Menurut Grosjean terdapat empat faktor, yaitu (1) partisipan, (2) situasi, (3) isi wacana, (4) fungsi interaksi. Aspek yang perlu diperhatikan dari faktor partisipan adalah (a) keahlian berbahasa, (b) pilihan bahasa yang dianggap lebih baik, (3) status sosial ekonomi, (d) usia, (e) jenis kelamim, (f) pendidikan, (g) pekerjaan, (h) latar belakang etnis, (i) relasi kekeluargaan, (j) keintiman, (k) sikap kepada bahasa-bahasa, dan (l) kekuatan luar yang menekan.

Dalam penelitian ini penulis mengkaji salah satu faktor yang berpengaruh dalam pemilihan bahasa yaitu faktor pekerjaan terhadap etnik Bugis di Kabupaten Donggala khususnya di Kecamatan Sojol Utara. Etnik Bugis di Kabupaten Donggala merupakan etnik pendatang (perantau) dari Sulawesi Selatan yang membawa bahasa dan budayanya sebagai alat berinteraksi antaretnik dan tetap mempertahankan budayanya untuk bersosialisasi dengan etnik setempat. Kabupaten Donggala khususnya Kecamatan Sojol Utara merupakan daerah tingkat dua di Sulawesi Tengah yang mayoritas penduduknya beretnik Dampal. Selain etnik Dampal, juga terdapat etnik Bugis, Kaili, Mandar, Jawa, dan Gorontalo.

Pemilihan bahasa dalam interaksi sosial masyarakat dwibahasa/multibahasa disebabkan oleh berbagai faktor sosial dan budaya. Evin-Tripp (1972) mengidentifikaskan empat faktor utama sebagai penanda pemilihan bahasa penutur dalam interkasi sosial, salah satunya adalah partisipan dalam interkasi. Faktor tersebut mencakup beberapa hal, salah satunya adalah tentang pekerjaan. Hal tersebut mengisyaratkan bahwa pekerjaan juga berpengaruh terhadap pola pemilihan bahasa seseorang. Tiap-tiap pekerjaan memiliki registernya masing-masing. Wardhaugh (2006) mendeskripsikan register sebagai suatu set language items 
yang berhubungan secara khusus dengan kelompok sosial atau kelompok pekerjaan (occupational) tertentu.

Ferguson (1994 dalam Wardhaugh, 2006) menjelaskan bahwa orang-orang yang berkutat dalam situasi komunikasi yang terus berulang cenderung mengembangkan kosakata, intonasi, dan kepingan karakteristik sintaksis dan fonologi yang serupa yang mereka gunakan dalam situasi-situasi tersebut. Variasi jenis inilah yang disebut register. Ferguson menambahkan bahwa istilahistilah khusus untuk objek-objek atau kejadian-kejadian tertentu yang berulang ini tampaknya membantu komunikasi agar semakin cepat. Register yang digunakan seseorang bisa merefleksikan latar belakang orang tersebut. Seseorang bisa mengontrol variasi register yang ia gunakan, seseorang mungkin saja memiliki lebih dari satu profesi. Tiap register akan membantu mengungkapkan siapa diri seseorang pada waktu dan tempat tertentu. Register ini juga bisa digunakan untuk mengukur apakah seseorang 'lebih baik' atau 'lebih buruk' daripada orang lain yang seprofesi dengannya. Dengan kata lain bahwa semakin bergengsi pekerjaan seseorang semakin luntur loyalitas terhadap bahasa pertamanya (b1-nya). Hal inilah yang ingin dibuktikan oleh penulis, apakah etnik Bugis yang mempunyai pekerjaan yang bergengsi (mapan) dapat melunturkan pemakaian dan pemilihan bahasa Bugisnya?

Kenyataan kebahasaan di Kabupaten

Donggala Kecamatan Sojol Utara tersebut menunjukkan kemajemukan masyarakatnya dan adanya saling pengertian dan toleransi yang tinggi dalam masyarakatnya. Dengan demikian, tepatlah bila dikatakan bahwa masyarakat Kabupaten Donggala Kecamatan Sojol Utara termasuk warga masyarakat plural yang memiliki toleransi dan saling menghargai.

Ada tiga masalah penelitian yang ingin dijawab dalam penelitian ini (1) bagaimanakah pola pemilihan bahasa etnik bugis dalam ranah keluarga berdasarkan kategori pekerjaan dan hubungan peran di Kabupaten Donggala? (2) faktor-faktor apakah yang mendasari pemilihan bahasa etnik Bugis dalam ranah keluarga berdasarkan kategori pekerjaan dan hubungan peran di Kabupaten Donggala?dan (3) apakah pekerjaan dapat mempengruhi pemilihan bahasa etnik Bugis yang ada di Kabupaten Donggala? Tujuan penelitian ini adalah (1) mendeskripsikan polapemilihan bahasa etnik bugis dalam ranah keluarga berdasarkan kategori pekerjaan dan hubungan peran di Kabupaten Donggala (2) menganalisis faktor-faktor yang mendasari pemilihan bahasa etnik Bugis dalam ranah keluarga berdasarkan kategori pekerjaan dan hubungan peran di Kabupaten Donggala, dan (3) mendeskripsikan pengaruh pekerjaan terhadap pemilihan bahasa etnik Bugis di Kabupaten Donggala.

Secara teoritis, penelitian ini diharapkan bermanfaat sebagai sumbangan bagi pengembangan khazanah keilmuan dalam kajian sosiolinguistik, khususnya dalam bidang pemilihan bahasa, ragam bahasa, dialek, dan variasi bahasa. Secara praktis, penelitian ini diharapkan sebagai usaha peningkatan saling pengertian antarmasyarakat pemakai bahasa yang bersangkutan dan usaha kesalahpahaman sebagai akibat penggunaan lebih dari satu bahasa. Selanjutnya, hasil penelitian ini bermanfaat dalam proses penentuan objek yang sama atau berbeda dari penelitian ini sehingga diperoleh informasi yang lebih komprehensif tentang pola-pola komunikasi dan pemilihan bahasa pada masyarakat multibahasa. 


\section{Teori dan Metode}

\subsection{Teori}

Pemilihan bahasa dalam interaksi sosial masyarakat dwibahasa/multibahasa disebabkan oleh berbagai faktor sosial dan budaya. Menurut Evin-Tripp (1972), ada empat faktor utama sebagai penanda pemilihan bahasa penutur dalam interaksi sosial, yaitu (1) latar (waktu dan tempat) dan situasi, (2) partisipan dalam interaksi, (3) topik percakapan, dan (4) fungsi interaksi.

Terkait dengan pola pemilihan bahasa pada masyarakat multibahasa, dikemukakan pendekatan kajian pemilihan bahasa. Fasold (1984: 183) mengemukakan bahwa dalam pemilihan bahasa ada tiga pendekatan yang dapat dilakukan, yaitu pendekatan sosiologi, psikologi sosial, dan antropologi.

Penulis dalam penelitian ini menggunakan pendekatan sosiologi, karena kajian ini berkaitan dengan analisis ranah. Pendekatan ini pertama kali dikemukakan oleh Fishman (1970). Menurut pola ini, ranah merupakan konstalasi faktor lokasi, topik, dan partisipan. Ditambahkannya (dalam Amir, 2010: 35) bahwa ranah adalah konsep teoritis yang menandai satu situasi interaksi yang didasarkan pada suatu pengalaman yang sama.

Sehubungan dengan uraian tersebut, teori yang digunakan dalam penelitian ini adalah teori pemilihan bahasa yang diadopsi dari teori Fishman yang mengemukakan bahwa dalam penggunaan bahasa ada konteks-konteks sosial yang melembaga (institusional context) yang disebut ranah. Ranah tersebut menurut Fishman (1972b:118), yaitu ranah keluarga, ranah ketetanggaan, ranah kerja, ranah agama, dan ranah pemerintahan.Namun, dalam penelitian ini difokuskan pada penggunaan bahasa dalam ranah keluarga berdasarkan hubungan peran dan kategori pekerjaan. Kategori pekerjaan dalam penelitian ini penulis membagi jenjang pekerjaan yaitu petani, PSN/TNI/POLRI, pedagang, pelajar, urusan rumah tangga (URT), tidak bekerja, dan pekerjaan lain.

Selanjutnya, hubungan peran yang digunakan komunikasi antara anggota keluarga, yaitu kakek/nenek, ayah/ibu, kakak/adik, putra/putri dan suami/istri dalam berbagai topik pembicaraan. Untuk melengkapi kajian tersebut, digunakan pula teori Platt, (1977) yang berpendapat bahwa dimensi identitas sosial merupakan faktor yang dapat memengaruhi penggunaan bahasa dalam masyarakat dwibahasa atau multibahasa. Dimensi itu mencakup umur, jenis kelamin, pekerjaan dan pendidikan.Namun, dalam penelitian ini hanya difokuskan pada dimensi kategori pekerjaan. Fokus tersebut dapat menggambarkan pola pemilihan bahasa etnik Bugis di Kecamatan Sojol Utara, Kabupaten Donggala.

\subsection{Metode}

Penelitian ini termasuk jenis penelitian lapangan dengan pendekatan sosiolinguistik. Oleh karena itu, pengkajian memakai pendekatan ilmuilmu sosial sebagaimana disarankan oleh Fasold (1984:183), suatu kajian sosiolinguistik melihat fenomena pemakaian bahasa sebagai fakta sosial yang menempatkan pemakaian suatu ragam bahasa sebagai sistem lambang (kode), sistem tingkah laku budaya yang berhubungan dengan pemakian bahasa dalam konteks yang sebenarnya.

Jenis data yang diambil berupa data kuantitatif dan kualitatif. Data kuantitatif diperoleh melalui penggunaan daftar tanyaan (kuesioner) berstruktur. Dalam kuesioner berstruktur, setiap pertanyaan disertai dengan alternatif jawaban secara lengkap atau kategori tertentu, (Aswantini, 2013:20). Data kualitatif diperoleh dengan teknik wawancara, 
observasi, dan perekaman berdasarkan teknik snowball sampling.

Penelitian ini berlokasi di Desa Ogoamas I dan Ogoamas II Kecamatan Sojol Utara Kabupaten Donggala. Kedua Desa tersebut dipilih karena merupakan basis komunitas etnis Bugis yang terbanyak dan masih jauh dari pengaruh lingkungan kota sehingga keaslian bahasa Bugis-nya masih nampak.

Berkaitan dengan itu, karena keterbatasan waktu penelitian, maka populasi penelitian ini hanya mengambil beberapa sampel sebagai objek yang diteliti atau hanya meneliti elemen sampel bukan elemen populasi. Jumlah sampel ditetapkan 92 responden dari 1017 jumlah penduduk kedua desa tersebut. Sebanyak 52 responden dari Desa Ogoamas I, dan 47 responden yang diambil dari Desa Ogoamas II. Perbedaan jumlah sampel tersebut karena populasi etnis Bugis di Desa Ogoamas I lebih banyak jika dibandingkan dengan populasi etnis Bugis yang ada di Desa Ogoamas II. Pengambilan sampel dilakukan dengan teknik sampel random (acak sederhana). Pengambilan 92 sampel tersebut diacak berdasarkan kategori pendidikan.

Hal itu sejalan dengan teori Gunarwan, (2002: 46) yang mengatakan bahwa untuk penelitian kebahasaan, sampel yang besar cenderung tidak perlu. Hal itu karena perilaku linguistik lebih homogen daripada perilakuperilaku lain.

Data yang diperoleh melalui kuesioner dianalisis dengan cara penghitungan persentase yang didasarkan pada jumlah jawaban yang masuk, Muhajir (1979: 30). Jawaban yang masuk adalah jawaban responden tentang informasi bahasa yang digunakan ketika berkomunikasi dengan nenek/kakek, ayah/ibu, adik/kakak, putra/putri, dan suami istri bagi yang telah berkeluarga.

\section{Pembahasan}

Data tentang pemilihan bahasa Bugis oleh etnik Bugis dalam ranah keluarga berdasarkan kategori pekerjaan dan hubungan peran di Kabupaten Donggala Kecamatan Sojol Utara diperoleh melalui jawaban responden dari pertanyaan yang terdaftar dalam kuesioner. Dalam kuesioner ditanyakan bahasa apakah yang digunakan responden ketika berbicara dengan kakek/nenek, ayah/ibu, kakak/adik, putra/putri, dan suami/istri (bagi responden yang sudah menikah), dan putra/putri (bagi responden yang sudah menikah) di rumah. Dalam pertanyaan tersebut terdapat empat pilihan jawaban, yaitu (a) bahasa Bugis, (b) bahasa Indonesia (c) campuran antara bahasa Bugis dan bahasa Indonesia, dan (d) bahasa lainnya yang ada di Kabupaten Donggala Kecamatan Sojol Utara. Keempat jawaban tersebut ditelaah berdasarkan dimensi identitas sosial yang mencakup kategori pekerjaan.

\subsection{Pola Pemilihan Bahasa Etnik Bugis dalam Ranah Keluarga Berdasarkan Kategori Jenjang Pekerjaan Petani dan Hubungan Peran}

Kategori jenjang petani dalam penelitian ini adalah responden yang bekerja sebagai petani, penambak, nelayan, dan tukang. Dari 92 jumlah responden, terdapat 15 responden yang bekerja sebagai petani, penambak, nelayan, dan tukang yang dikategorikan sebagai petani. Berikut adalah tabel pola pemilihan bahasa oleh etnik Bugis dalam ranah keluarga berdasarkan kategori jenjang pekerjaan petani dan hubungan peran. 
Tabel 1

Pola Pemilihan Bahasa etnik Bugis dalam Ranah Keluarga Berdasarkan Kategori Jenjang PekerjaanPetani dan Hubungan Peran Kakek/Nenek, Ayah/Ibu, Kakak/Adik, Putra/Putri dan Suami/Istri

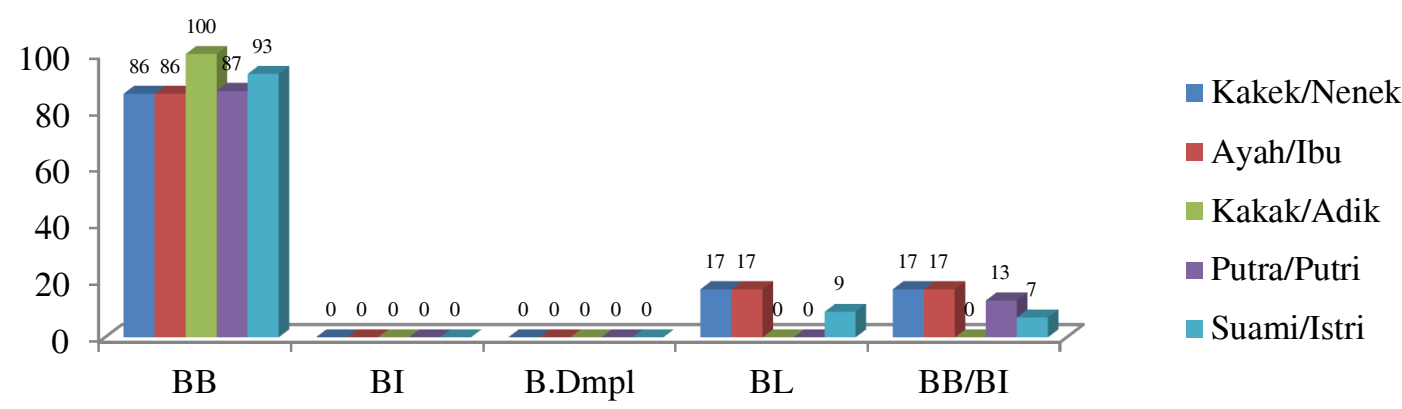

Sumber: data primer

Keterangan:

$\mathrm{BB}=$ bahasa Bugis

$\mathrm{BI}=$ bahasa Indonesia

B. Dmpl= bahasa Dampal

$\mathrm{BL}=$ bahasa lain

$\mathrm{BB}, \mathrm{BI}=$ bahasa Bugis, bahasa Indonesia

Dalam kategori

jenjang pekerjaanpetani data yang terjaring sebanyak 15 responden. Sesuai dengan data yang tertera pada gambar 1 hasil penelitian menunjukkan bahwa pemilihan bahasa pada kategori jenjang pekerjaanpetaniberdasarkan hubunganperan, kelompok jenjang pendidikan petani apabila bercakap-cakap dengan kakek/nenek masih didominasi pemilihan bahasa Bugis. Sebanyak 13 responden $(86 \%)$ yang menggunakan $\mathrm{BB}$, 1 responden (17\%) yang menggunakan BL yaitu bahasa Mandar dan juga 1 responden $(17 \%)$ yang bercampur kode antara bahasa Bugis dan bahasa Indonesia. Hal ini menggambarkan bahwa para responden yang bekerja sebagai petani apabila bercakap-capak dengan kakek atau nenek mereka masih lebih dominan menggunakan BB.

Kategori hubungan peran Bapak/ Ibu, sesuai dengan data yang tertera pada gambar 1, hasil penelitian menunjukkan bahwa pemilihan bahasa pada kategori jenjang pekerjaan petani berdasarkan hubungan-peran, kelompok jenjang pekerjaan petani apabila bercakap-cakap dengan ayah/ibu juga masih didominasi pemilihan bahasa Bugis. Sebanyak 13 responden (86\%) yang menggunakan BB 1 responden (17\%) yang menggunakan BL (bahasa Kaili) dan juga ada 1 responden $(17 \%)$ yang menggunakan bahasa campuran antara bahasa Bugis dan bahasa Indonesia.

Selanjutnya, kategori hubungan peran putra/putri hasil penelitian menunjukkan bahwa bahasa pada kategori jenjang pekerjaan petani berdasarkan hubungan-peran, apabilaapabila bercakap-cakap dengan kakak/adik, semua responden (100\%) memilih menggunakan BB. Lebih lanjut, sesuai dengan data yang tertera pada gambar 1, hasil penelitian menunjukkan bahwa pemilihan bahasa pada kategori jenjang pekerjaan petani berdasarkan hubungan-peran apabila bercakap-cakap dengan suami/istri sebanyak 93\% (14 responden) yang memilih $\mathrm{BB}$ dan hanya ada 1 responden $(7 \%)$ yangbercampur kode antara bahasa Bugis dan bahasa Indonesia.

Dengan demikian, dapat digambarkan pola pemilihan bahasa etnis Bugis dalam ranah keluarga berdasarkan kategori jenjang pekerjaan petani dan hubungan peran seperti berikut ini. 


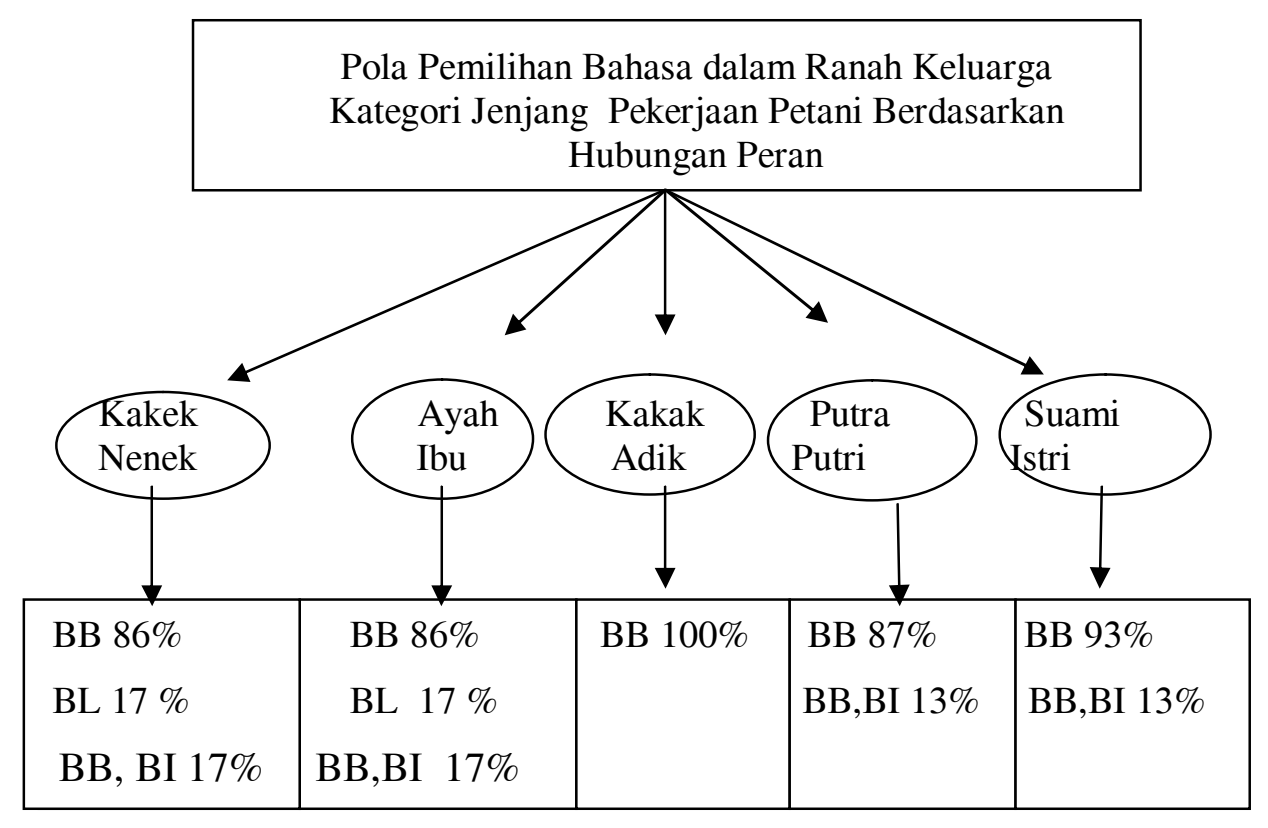

3.2 Pola Pemilihan Bahasa Etnik Bugis responden yang bekerja sebagai dalam Ranah Keluarga PNS/TNI/Polri. Berikut adalah tabel Berdasarkan Kategori Jenjang pola pemilihan bahasa oleh etnik Bugis Pekerjaan PNS/TNI/Polri dan dalam ranah keluarga berdasarkan Hubungan Peran kategori jenjang pekerjaan Kategori jenjang PNS/TNI/Polri yang PNS/TNI/Polri dan hubungan peran. terjaring dari 92 responden sebanyak 11

Tabel 2

Pola Pemilihan Bahasa etnik Bugis dalam Ranah Keluarga Berdasarkan Kategori Jenjang Pekerjaan PNS/TNI/Polri dan Hubungan Peran Kakek/Nenek, Ayah/Ibu, Kakak/Adik, Putra/Putri, dan Suami/Istri

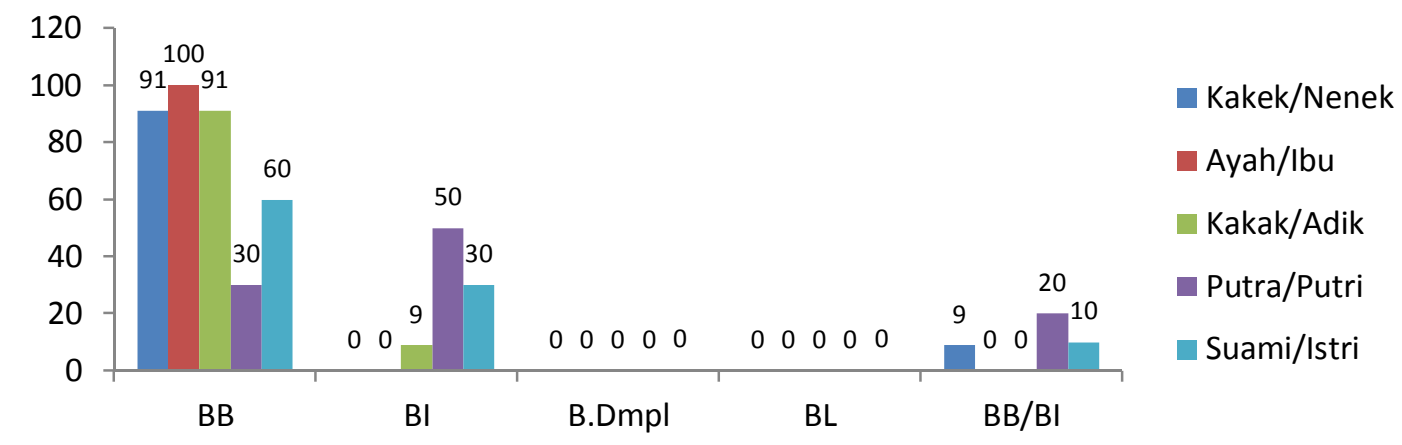

Sumber: data primer

Dalam kategori jenjang pekerjaan PNS/TNI/Polri data yang terjaring sebanyak 11 responden. Sesuai dengan data yang tertera pada gambar 2 hasil penelitian menunjukkan bahwa pemilihan bahasa pada kategori jenjang pekerjaan PNS/TNI/Polri berdasarkan hubungan- peran, kelompok jenjang pendidikan PNS/TNI/Polri apabila bercakap-cakap dengan kakek/nenek masih didominasi pemilihan bahasa Bugis. Sebanyak 10 responden (91\%) yang menggunakan BB dan hanya 1 responden (9\%) yang menggunakan bahasa campuran yaitu BB 
dan BI. Hal ini menggambarkan bahwa para responden yang bekerja sebagai PNS/TNI/Polri apabila bercakap-capak dengan kakek atau nenek mereka masih lebih dominan menggunakan BB.

Kategori hubungan peran Bapak/ Ibu, sesuai dengan data yang tertera pada gambar 2, hasil penelitian menunjukkan bahwa pemilihan bahasa pada kategori jenjang pekerjaan PNS/TNI/Polri berdasarkan hubungan-peran, kelompok jenjang pekerjaan PNS/TNI/Polri apabila bercakap-cakap dengan ayah/ibu semua responden $(100 \%)$ menggunakan BB. Selanjutnya, hasil penelitian menunjukkan bahwa pemilihan bahasa pada kategori jenjang pekerjaan PNS/TNI/Polri berdasarkan hubunganperan, kelompok jenjang pekerjaan PNS/TNI/Polri apabila bercakap-cakap kakak/adik sebanyak (91\%) memilih menggunakan BB dan selebihnya (9\%) menggunakan BI
Lebih lanjut, kategori hubungan peran putra/putri hasil penelitian menunjukkan bahwa penggunaan BB agak tergeser dari pemilihan BI. Penggunaan BB hanya $30 \%$ dan sebanyak $50 \%$ yang memilih menggunakan BI. Sementara, sebanyak $20 \%$ yang menggunakan bahasa campuran BI dan BB. Percakapan antara suami dan istri dalam ranah keluarga etnik Bugis masih lebih dominan menggunakan BB yaitu sebanyak $(60 \%)$, (30\%) yang menggunakan BI dan hanya (10\%) yang menggunakan bahasa campuran antara BI dan BB.

Dengan demikian, dapat digambarkan pola pemilihan bahasa etnis Bugis dalam ranah keluarga berdasarkan kategori jenjang pekerjaan PNS/TNI/Polri dan hubungan peran seperti berikut ini.

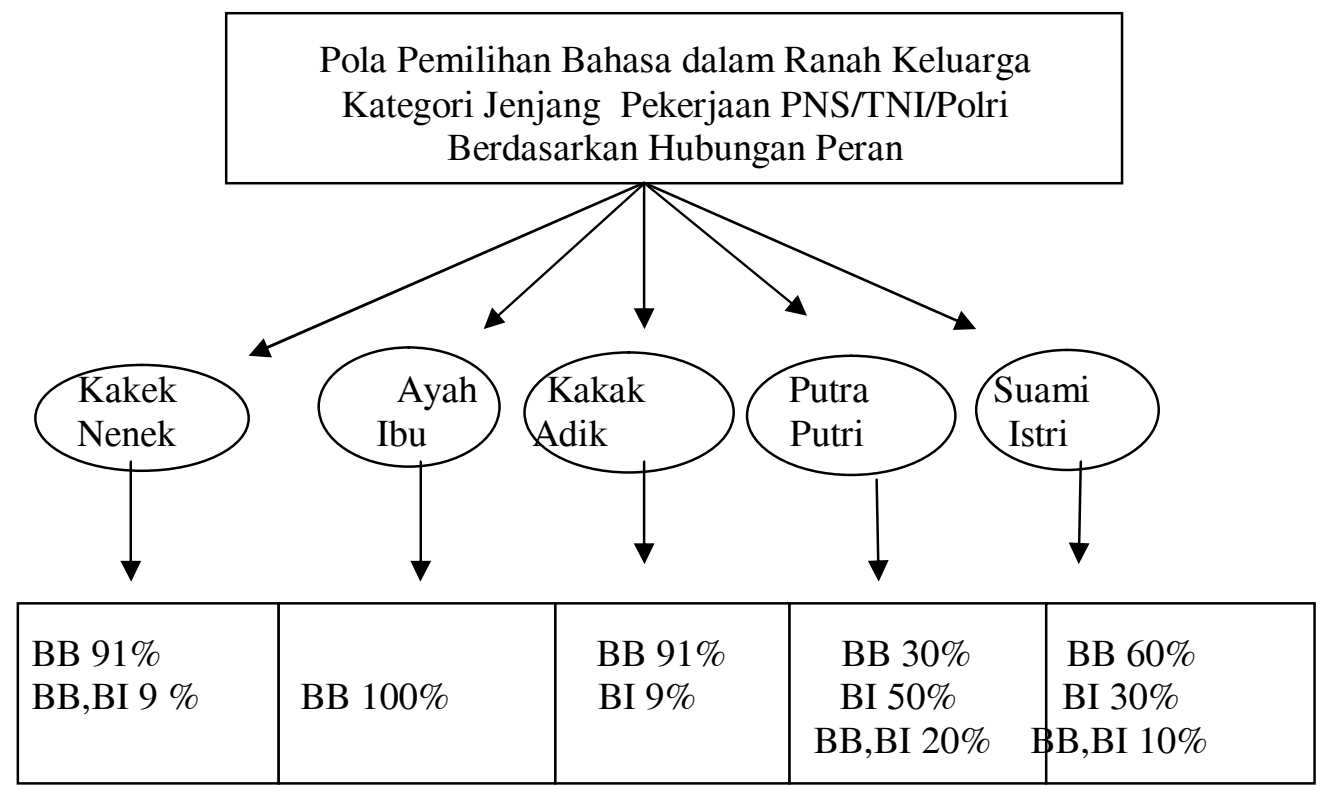

3.3 Pola Pemilihan Bahasa Etnik Bugis yang bekerja sebagai pedagang. Berikut dalam Ranah Keluarga adalah tabel pola pemilihan bahasa oleh Berdasarkan Kategori Jenjang etnik Bugis dalam ranah keluarga Pekerjaan Pedagang dan berdasarkan kategori jenjang pekerjaan Hubungan Peran

Kategori jenjangpedagang yang terjaring pedagang dan hubungan peran. dari 92 responden sebanyak 15 responden 
Tabel 3

Pola Pemilihan Bahasa etnik Bugis dalam Ranah Keluarga Berdasarkan Kategori Jenjang Pekerjaan Pedagang dan Hubungan Peran Kakek/Nenek, Ayah/Ibu, Kakak/Adik, Putra/Putri, dan Suami/Istri

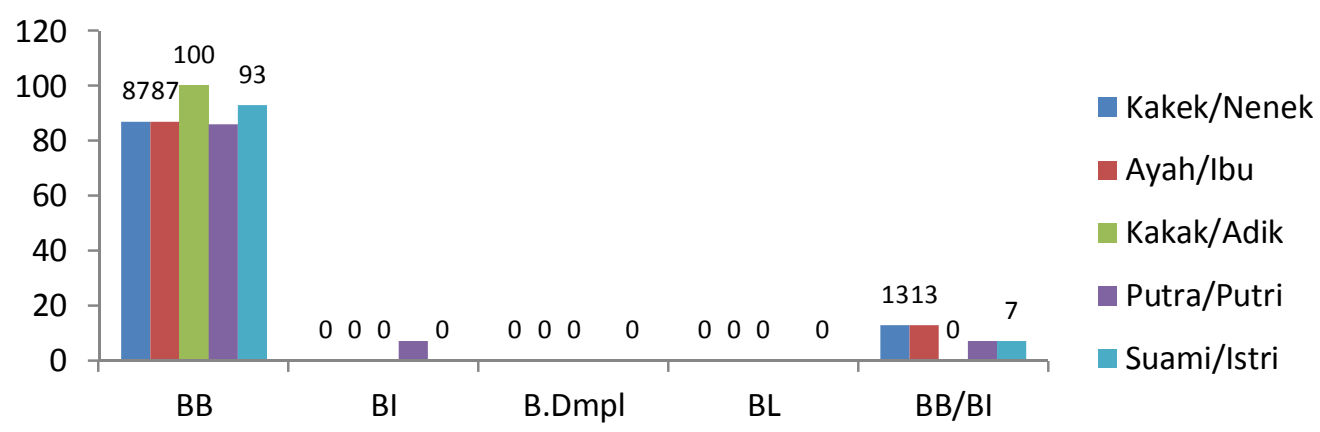

Sumber: data primer

Dalam kategori jenjang pekerjaan pedagang data yang terjaring sebanyak 15 responden. Sesuai dengan data yang tertera pada gambar 3 hasil penelitian menunjukkan bahwa pemilihan bahasa pada kategori jenjang pedagangberdasarkan hubungan-peran, kelompok jenjang pekerjaanpedagang apabila bercakap-cakap dengan kakek/nenek masih didominasi pemilihan bahasa Bugis. Sebanyak 13 responden $(87 \%)$ yang menggunakan $\mathrm{BB}$ dan hanya 2 responden (13\%) yang menggunakan bahasa campuran yaitu BB dan BI. Kategori hubungan peran Bapak/ Ibu, sesuai dengan data yang tertera pada gambar 3 , hasil penelitian menunjukkan bahwa pemilihan bahasa pada kategori jenjang pekerjaan pedagang berdasarkan hubungan-peran, kelompok jenjang pekerjaan pedagang apabila bercakap-cakap dengan ayah/ibu sebanyak 13 responden $(87 \%)$ menggunakan $\mathrm{BB}$ dan 2 responden (13\%) yang menggunakan bahasa campuran $\mathrm{BB}$ dan BI.
Selanjutnya, hasil penelitian menunjukkan bahwa pemilihan bahasa pada kategori jenjang pekerjaan pedagang berdasarkan hubungan-peran, kelompok jenjang pekerjaan pedagang apabila bercakap-cakap kakak/adik semua responden (100\%) memilih menggunakan BB.Lebih lanjut, kategori hubungan peran putra/putri hasil penelitian menunjukkan bahwa penggunaan $\mathrm{BB}$ masih dominan digunakan yaitu sebanyak 13 responden (86\%) yang memilih menggunakan BB. Percakapan antara suami dan istri dalam ranah keluarga etnik Bugis juga masih lebih dominan menggunakan BB yaitu sebanyak (93\%), menggunakan BB dan hanya 1 responden (7\%) yang menggunakan BI.

Dengan demikian, dapat digambarkan pola pemilihan bahasa etnis Bugis dalam ranah keluarga berdasarkan kategori jenjang pekerjaan pedagang dan hubungan peran seperti berikut ini. 


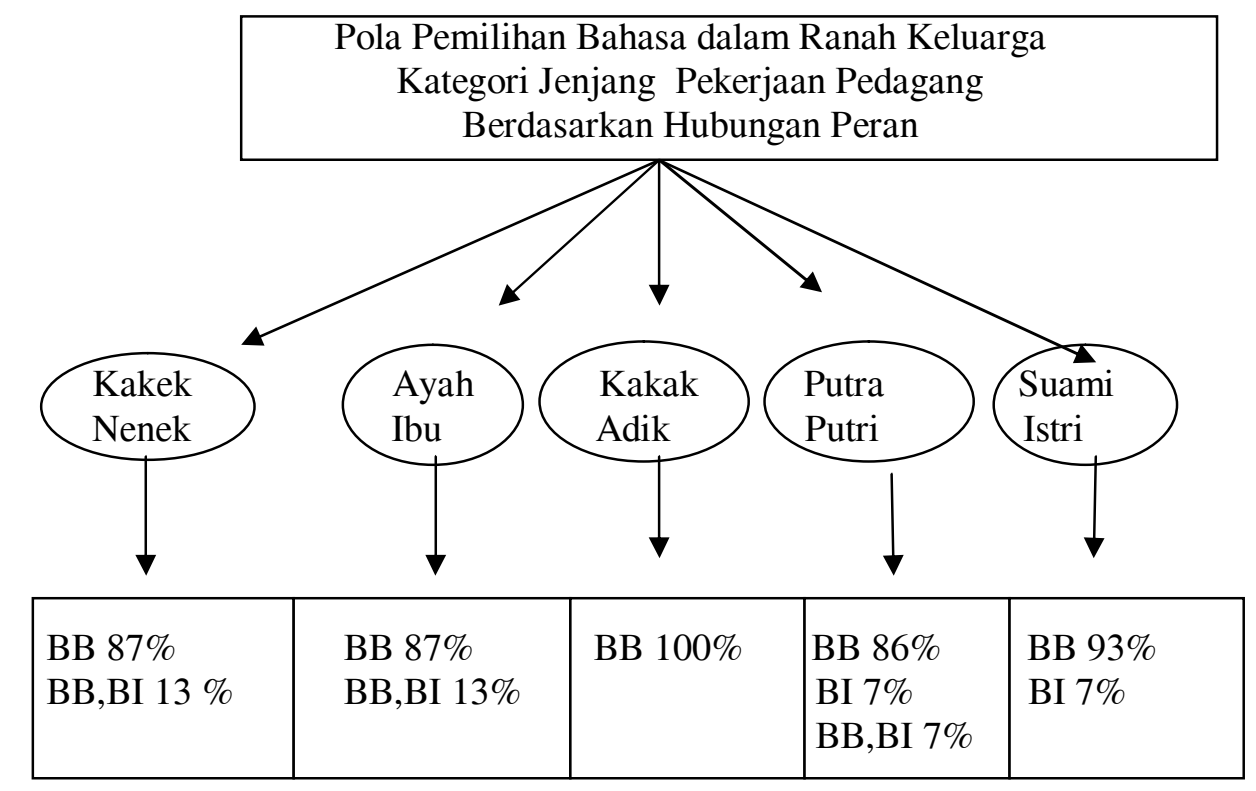

3.4 Pola Pemilihan Bahasa Etnik Bugis yang berprofesi sebagai pelajar. Berikut dalam Ranah Keluarga adalah tabel pola pemilihan bahasa oleh Berdasarkan Kategori Jenjang etnik Bugis dalam ranah keluarga Pekerjaan Pelajar dan Hubungan berdasarkan kategori jenjang pekerjaan Peran pelajar dan hubungan peran.

Kategori jenjang pelajar yang terjaring dari 92 responden sebanyak 29 responden

Tabel 4

Pola Pemilihan Bahasa etnik Bugis dalam Ranah Keluarga Berdasarkan Kategori Jenjang Pekerjaan Pelajar dan Hubungan Peran Kakek/Nenek, Ayah/Ibu, dan Kakak/Adik

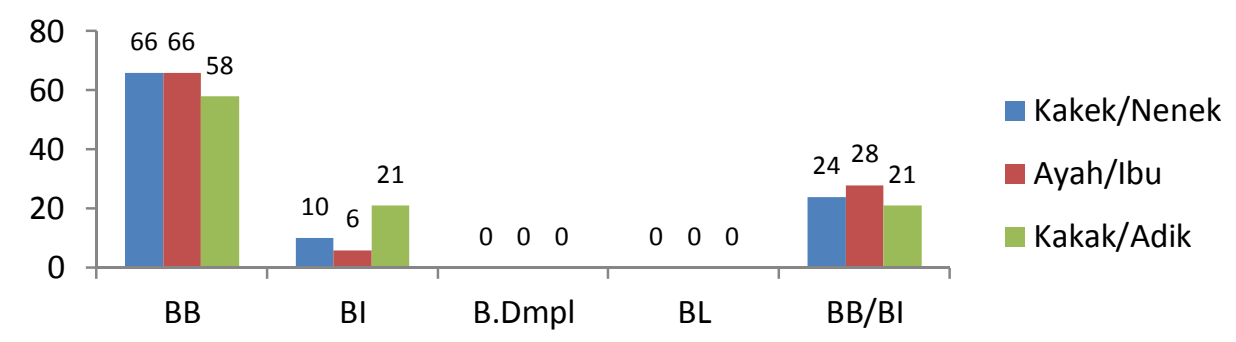

Sumber: data primer

Dalam kategori jenjang pekerjaan pelajar data yang terjaring sebanyak 29 responden. Sesuai dengan data yang tertera pada gambar 4 hasil penelitian menunjukkan bahwa pemilihan bahasa pada kategori jenjang pelajar berdasarkan hubungan-peran, kelompok jenjang pekerjaan pelajar apabila bercakap-cakap dengan kakek/nenek sebanyak 19 responden (66\%) yang menggunakan BB, 3 responden (10\%) yang menggunakan
BI dan 7 responden (24\%) yang menggunakan bahasa campuran BI dan BB. Kategori hubungan peran Ayah/ Ibu, sesuai dengan data yang tertera pada gambar 4, hasil penelitian menunjukkan bahwa pemilihan bahasa pada kategori jenjang pekerjaan pelajar berdasarkan hubungan-peran, kelompok jenjang pekerjaan pelajar apabila bercakapcakap dengan ayah/ibu sebanyak 19 responden (66\%) menggunakan $\mathrm{BB}$ dan 2 
responden $(6 \%)$ yang menggunakan BI dan 8 responden (28\%) yang menggunakan bahasa campuran $\mathrm{BB}$ dan BI.

Selanjutnya, hasil penelitian menunjukkan bahwa pemilihan bahasa pada kategori jenjang pekerjaan pelajar berdasarkan hubungan-peran, kelompok jenjang pekerjaan pelajar apabila bercakap-cakap kakak/adik sebanyak 17 responden (58\%) yang menggunakan $\mathrm{BB}$, 6 responden $(21 \%)$ yang menggunakan
BI dan juga ada 6 responden (21\%) yang menggunakan bahasa campuran BB dan BI. Hubungan peran kakak/adik dan putra/putri dalam kategori pekerjaan pelajar belum ada karena semua yang berstatus pekerjaan belum ada yang menikah.

Dengan demikian, dapat digambarkan pola pemilihan bahasa etnis Bugis dalam ranah keluarga berdasarkan kategori jenjang pekerjaan pedagang dan hubungan peran seperti berikut ini.

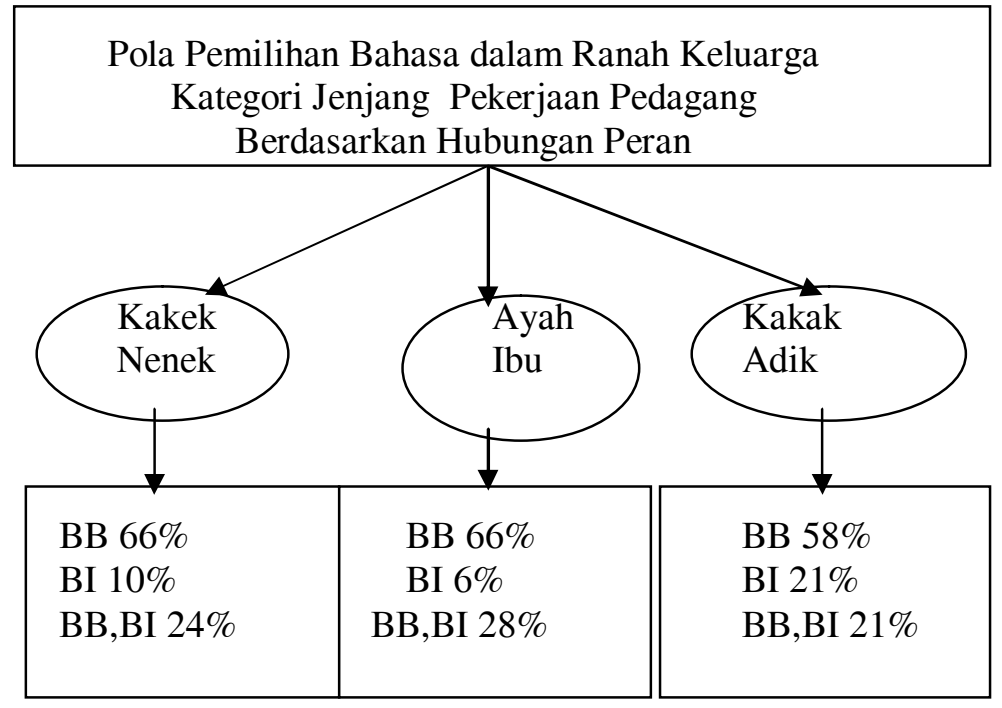

3.5 Pola Pemilihan Bahasa Etnik Bugis responden sebanyak 8 responden yang dalam Ranah Keluarga bekerja sebagai URT. Berikut adalah Berdasarkan Kategori Jenjang tabel pola pemilihan bahasa oleh etnik Pekerjaan Urusan Rumah Tangga Bugis dalam ranah keluarga berdasarkan (URT) dan Hubungan Peran Kategori jenjang pekerjaan urusan rumah hubungan peran. tangga (URT) yang terjaring dari 92

Pola Pemilihan Bahasa etnik Bugis dalam Ranah Keluarga Berdasarkan Kategori Jenjang Pekerjaan URT dan Hubungan Peran Kakek/Nenek, Ayah/Ibu, Kakak/Adik, Putra/Putri, dan Suami/Istri 


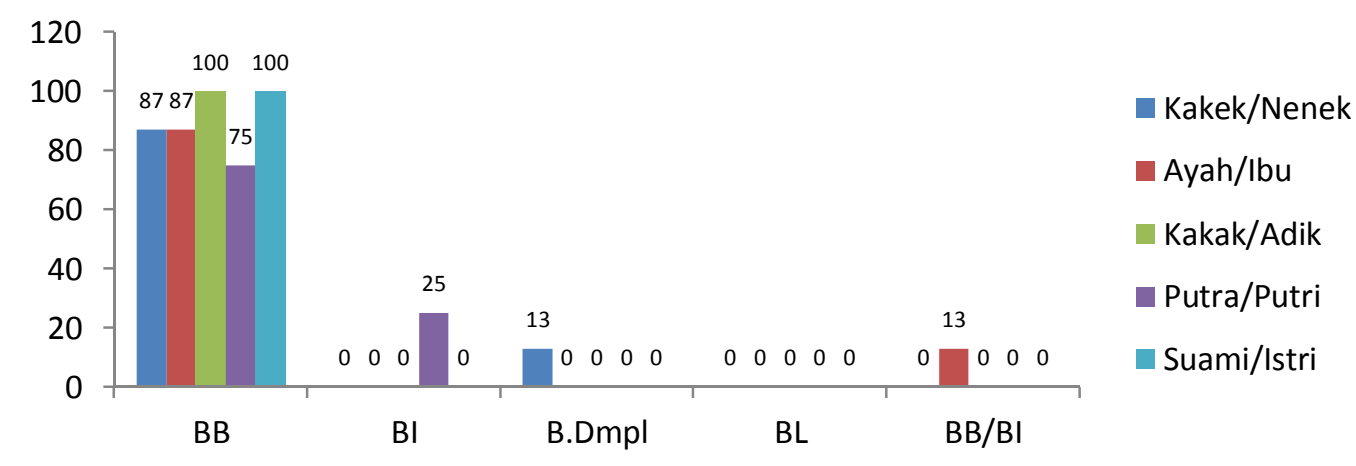

Sumber: data primer

Dalam kategori jenjang pekerjaan URT data yang terjaring sebanyak 8 responden. Sesuai dengan data yang tertera pada gambar 5 hasil penelitian menunjukkan bahwa pemilihan bahasa pada kategori jenjang URTberdasarkan hubungan-peran, kelompok jenjang pekerjaan URT apabila bercakap-cakap dengan kakek/nenek masih didominasi pemilihan bahasa Bugis. Sebanyak 7 responden $(87 \%)$ yang menggunakan $\mathrm{BB}$ dan hanya 1 responden (13\%) yang menggunakan BDmpl. Kategori hubungan peran Ayah/ Ibu, sesuai dengan data yang tertera pada gambar 5, hasil penelitian menunjukkan bahwa pemilihan bahasa pada kategori jenjang pekerjaan URT berdasarkan hubungan-peran, kelompok jenjang pekerjaan URT apabila bercakap-cakap dengan ayah/ibu sebanyak 7 responden $(87 \%)$ menggunakan $\mathrm{BB}$ dan 1 responden $(13 \%)$ yang menggunakan bahasa campuran BB
Selanjutnya, hasil penelitian menunjukkan bahwa pemilihan bahasa pada kategori jenjang pekerjaan URT berdasarkan hubungan-peran, kelompok jenjang pekerjaan URT apabila bercakap-cakap kakak/adik semua responden (100\%) memilih menggunakan BB. Lebih lanjut, kategori hubungan peran putra/putri hasil penelitian menunjukkan bahwa penggunaan $\mathrm{BB}$ masih dominan digunakan yaitu sebanyak 6 responden (75\%) yang memilih menggunakan BB. Percakapan antara suami dan istri dalam ranah keluarga etnik Bugis kategori jenjang pekerjaan URT (100\%) memilih menggunakan BB.

Dengan demikian, dapat digambarkan pola pemilihan bahasa etnis Bugis dalam ranah keluarga berdasarkan kategori jenjang pekerjaan URT dan hubungan peran seperti berikut ini. dan BI.

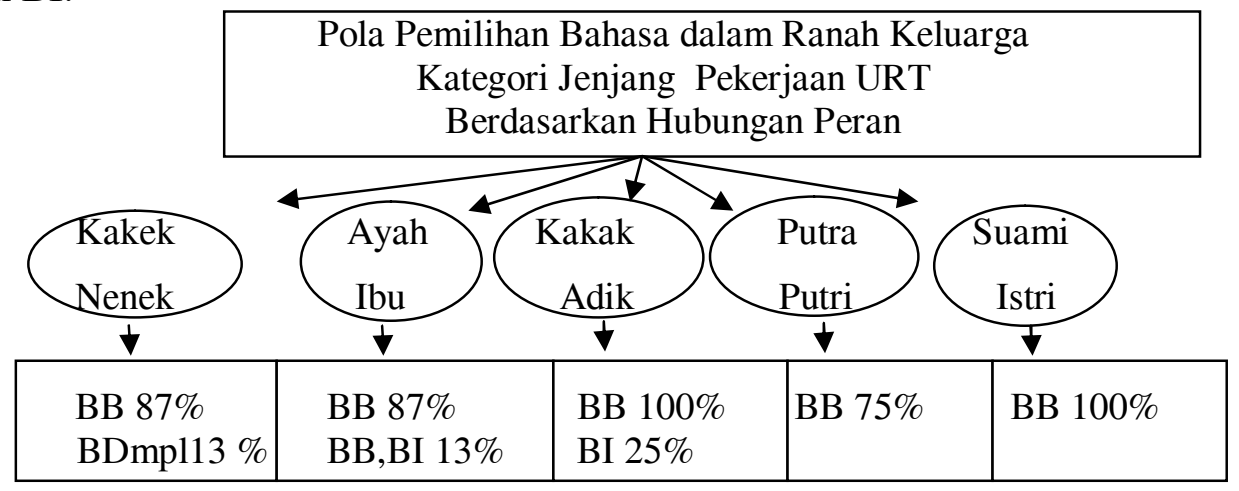


3.6 Pola Pemilihan Bahasa Etnik Bugis dalam Ranah Keluarga Berdasarkan Kategori Jenjang Pekerjaan Pekerjaan Lain (PL) dan Hubungan Peran

Kategori jenjang pekerjaan lain (PL) 92 responden sebanyak 11 responden yang

\section{Tabel 6}

Pola Pemilihan Bahasa etnik Bugis dalam Ranah Keluarga Berdasarkan Kategori Jenjang Pekerjaan PL dan Hubungan Peran Kakek/Nenek, Ayah/Ibu, Kakak/Adik, Putra/Putri, dan Suami/Istri

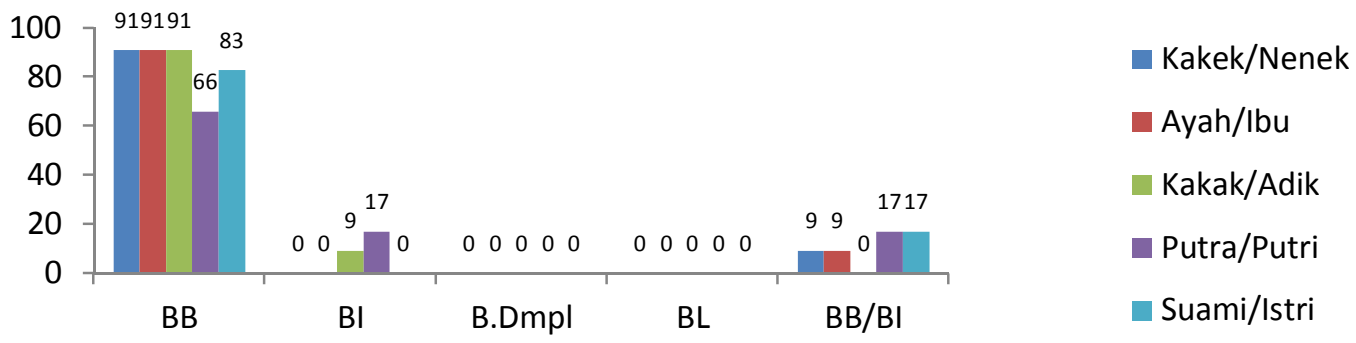

bekerja sebagai guru honorer, pegawai honorer, dan pegawai swasta (PL). Berikut adalah tabel pola pemilihan bahasa oleh etnik Bugis dalam ranah keluarga berdasarkan kategori jenjang pekerjaan PL dan hubungan peran.

Sumber: data primer

Dalam kategori jenjang pekerjaan guru honorer, pegawai honorer dan pegawai swasta (PL) data yang terjaring sebanyak 11 responden. Sesuai dengan data yang tertera pada gambar 6 hasil penelitian menunjukkan bahwa pemilihan bahasa pada kategori jenjang PL berdasarkan hubungan-peran, kelompok jenjang pekerjaan PL apabila bercakapcakap dengan kakek/nenek masih didominasi pemilihan bahasa Bugis. Sebanyak 10 responden (91\%) yang menggunakan BB dan hanya 1 responden (9\%) yang menggunakan bahasa campuran BB,BI. Kategori hubungan peran Ayah/ Ibu, sesuai dengan data yang tertera pada gambar 6 , hasil penelitian menunjukkan bahwa pemilihan bahasa pada kategori jenjang pekerjaan PL berdasarkan hubungan-peran, kelompok jenjang pekerjaan PL apabila bercakapcakap dengan ayah/ibu sebanyak 10 responden (91\%) menggunakan BB dan 1 responden $(9 \%)$ yang menggunakan bahasa campuran BB dan BI. 


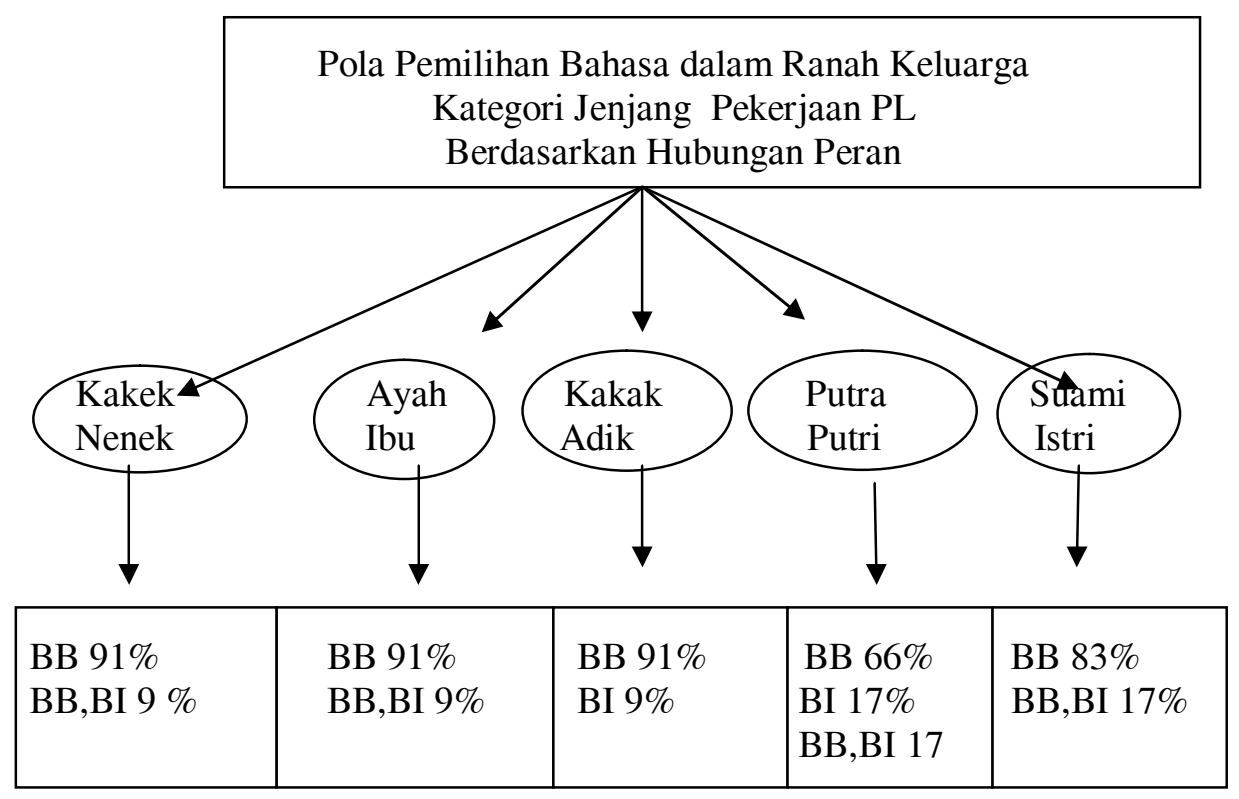

\section{Simpulan}

Pola pemilihan bahasa etnik Bugis di Kabupaten Donggala dalam ranah keluarga berdasarkan kategori pekerjaan dan hubungan peran (kakek/nenek, ayah/ibu, kakak/adik, putra/puti, dan suami/istri seperti berikut ini.

$$
\begin{aligned}
& \text { Kategori Petani } \rightarrow \text { BB 91\% } \rightarrow \text { BL 7\% } \rightarrow \text { BB, BI 12\% } \\
& \text { Kategori PNS/TNI/Polri } \rightarrow \text { BB 74\% } \rightarrow \text { BI 18\% } \rightarrow \text { BB,BI 6\% } \\
& \text { Kategori Pedagang } \rightarrow \text { BB 90\% } \rightarrow \text { BI 3\% } \rightarrow \text { BB,BI7\% } \\
& \text { Kategori Pelajar } \rightarrow \text { BB 63\% } \rightarrow \text { BI 13\% } \rightarrow \text { BB,BI 24\% } \\
& \text { Kategori URT } \rightarrow \text { BB 90 } \rightarrow \text { BI 4\% } \rightarrow \text { B.Dmpl 3\% } \rightarrow \text { BB,BI 3\% } \\
& \text { Kategori PL } \rightarrow \text { BB 84\% } \rightarrow \text { BI 5\% } \rightarrow \text { BB,BI 11 }
\end{aligned}
$$

Berdasarkan pola pemilihan bahasa etnik Bugis dalam ranah keluarga berdasarkan kategori pekerjaan, responden yang bekerja sebagai petani, pedagang, dan URT yang memilih menggunakan BB di atas $90 \%$. Sementara, yang paling rendah pemilihan BB-nya adalah responden yang bekerja sebagai pelajar dan PNS/TNI/Polri. Hal ini mengindikasikan bahwa pekerjaan yang dilandasi dengan pendidikan tinggi berpengaruh terhadap pola pemilihan bahasanya. Orang yang mempunyai pekerjaan dilandasi dengan pendidikan tinggi, maka loyalitas pemilihan B1-nya akan semakin luntur. Hal ini pula yang terjadi pada etnik Bugis yang ada di perantauan Kabupaten
Donggala, Sulawesi Tengah. Namun, kelunturan loyalitas tersebut masih dalam batas rendah sehingga kebertahanan $\mathrm{BB}$ masih dalam tahap aman.

Dominannya pemilihan BB sebagai bahasa pengantar dalam keluarga disebabkan oleh faktor sikap positif terhadap bahasanya yaitu BB. Di samping itu, etnik Bugis fanatik terhadap bahasanya walaupun berada di perantauan. Faktor-faktor yang mendasari pemilihan bahasa etnik Bugis dalam ranah keluarga berdasarkan kategori pekerjaan dan hubungan peran di Kabupaten Donggalaadalah loyalitas terhadap bahasanya, bahasa Bugis, (2) bangga terhadap bahasanya, 
bahasa Bugis, (3) kesadaran adanya norma bahasa, dalam bahasa Bugis.

\section{Daftar Pustaka}

Amir, Johar. 2010. "Pola Pemilihan Bahasa pada Ranah Keluarga di Kabupaten Pangkajene

Kepulauan". Disertasi. Makassar: Universitas Hasanuddin.

Aswantini, 2013. "Sumber dan Koleksi Data (Bidang IPS)". Modul. Diklat Jabatan Fungsional Peneliti Tingkat Pertama. Bogor: Lembaga Ilmu Pengetahuan Indonesia.

Ervin-Tripp, S.M. 1972. "Sociolinguistic Rules of Address". Dalam John B. Pride and Janet Holmes (eds.) Sociolinguistics. Harmondsworth: Penguin, 225 -240.

Herawati, 2014. "Pemilihan Bahasa Tutur Konjo dalam Masyarakat di Sinjai”. Disertasi. Yogyakarta: Universitas Gadjah Mada.

Hunt, C.L. 1972. "Language Choice in a Multilingual Society". Dalam Lieberson, Stanley (ed.) Exploration in Sociolinguistics, Bloomington: Indiana University, $112-125$.

Fasold, Ralph. 1984. The Sociolinguistic of Society. Oxford: Basil Blackwell.

Fishman, Joshua A. (Ed.). 1972a. Reading in the Sociology of Language. Paris: Mouton. (rujukanBuku)

1972b. The Sociology of Language. Massachussetts: Newburry House.

Gunarwan, $\quad$ Asim. 2002. PedomanPenelitianPemakaianBa hasa.Jakarta: Pusat Bahasa, DepartemenPendidikan Nasional.

Muhajir.1979. Fungsi dan Kedudukan Dialek Jakarta: Jakarta: Pusat Pembinaan dan Pengembangan Bahasa.
Poedjosoedarmo, S. 1975. "Kode dan Alih Kode" dalam Widyaparwa.Yogyakarta: Balai Penelitian Bahasa.

Platt, J.T. 1977. Code Selection in a Multilingual Polyglossic Society. Oxford: Pergamon Press.

Wardhaugh, Ronald. 2006. An Introduction to Sociolinguistics. Oxford: Blackwell publishing. 